\title{
Performance of Shear Connector in Composite Slab and Steel Beam with Reentrant and Open Trough Profiled Steel Sheeting
}

\author{
Alemu Feyissa ${ }^{1}$ and Goshu Kenea $\mathbb{1}^{2}$ \\ ${ }^{1}$ Civil Engineering Department, College of Engineering and Technology, Mettu University, Mettu, Oromia, Ethiopia \\ ${ }^{2}$ Civil Engineering Department, Jimma Institute of Technology, Jimma University, Jimma, Oromia, Ethiopia \\ Correspondence should be addressed to Goshu Kenea; goshukeneatujuba@gmail.com
}

Received 29 November 2021; Accepted 17 January 2022; Published 10 February 2022

Academic Editor: Iman Mansouri

Copyright (C) 2022 Alemu Feyissa and Goshu Kenea. This is an open access article distributed under the Creative Commons Attribution License, which permits unrestricted use, distribution, and reproduction in any medium, provided the original work is properly cited.

\begin{abstract}
The composite construction strategies realize an increasing number of sizeable applications in regions like bridges, ramps, homes, and different exceptional places. The component of composite structure considered in the study contains composite slab, profiled steel sheeting, steel beam, shear connector, and reinforcement cages. The investigation mainly focused on the structural performance of demountable shear connectors in composite slabs and steel beams with profiled steel sheeting. An extensive nonlinear finite element model was used to carry out in FE software Abaqus 6.14. Nonlinear behavior of concrete, stud connector, profiled steel sheeting, reinforcement cage, and steel beam are included in the finite element model. In this study, 24 specimens were taken into consideration to investigate the capacity of the shear connection, the load-slip curve of stud, failures modes of demountable shear connectors, and concrete crushing in the composite floor with profiled steel sheeting. The analysis confirmed that as the diameter of the shear connector increased from 19 to $22 \mathrm{~mm}$, the capacity of the shear connector also increased by $54.313 \%$ and $28.903 \%$ in both open through and reentrant profiled steel sheeting, respectively. In addition, as the height of the profiled steel sheeting increased from 50 to $64 \mathrm{~mm}$, the capacity of the shear connector is increased by $11.601 \%$ and $32.564 \%$ in open through and reentrant profiled steel sheeting, respectively. Similarly, when the concrete grade increased from C-40 to C-60, the capacity of the shear connector also increased by $70.128 \%$ and $48.301 \%$ with open and reentrant profiled steel sheeting, respectively. Furthermore, sensitivity analysis is done to see how much each input parameters affect the output parameter.
\end{abstract}

\section{Introduction}

Composite structures are more widely used and applicable in different construction areas throughout the world. Those structures are created by combining two or more structural elements to act as a single structural element, where each component behaves in a structurally efficient manner. The physical properties of each material combined to form a single unit that acts as a one-unit structure having a better performance than its separate parts. The system is not only about safety; it also considers the economy as the main criterion. In steel-concrete composite structures, the concrete is good in compression, and the steel is good in tension. The combination results in a highly efficient structural performance taking safety and economy as the primary consideration.
Therefore, a detailed investigation is required to provide design with safety, economic, and sustainable structure.

In the composite structures, concrete floor slabs may be used with and without profiled steel sheeting, which can act as steel reinforcement in positive bending moment regions. Experimental and numerical investigations have been undertaken to look into shear bearing capacity, failure modes, average slip, ductility, and stiffness of different types of connectors in composite slab-beam structures without profiled steel sheeting [1-6]. According to the paper [7], an extensive experimental test was conducted on the overall performance of stud connectors in high-strength structural steel and ultra-high-performance concrete composite beam, including slab under static loading. The shear capacity, strength, and stiffness have been investigated by considering 
the diameter and arrangements of the shear connectors as primary study parameters. The result verified the stud shank failure due to high-strength concrete grade and weak ductility when compared to normal concrete strength. In addition, an experiment has been undertaken to study the behavior of demountable bolt shear connectors composite structure without profiled steel sheeting under cyclic loading [8]. In the study, the size and strength of the bolt are the main parameters. Monotonic loading is also considered in the study to see the effect of cyclic loading, which resulted in cyclic degradation.

In another case, some studies have been conducted on the behavior of composite structures made from the concrete slab with profiled steel sheeting and steel I-section beam, both experimentally and numerically [9-13]. The studies are mainly focused on the strength, stiffness, shear, and flexural behavior of the composite structures by considering the different forms of stud connectors as principal parameters. Moreover, an experimental study has been undertaken on the shear capacity of connector and failure mode of composite beam with profiled steel sheeting under static and impact loading [14]. In addition, an experimental investigation is also carried out to access the shear strength, stiffness, and ductility of demountable shear connectors in composite structures, that are made from concrete cone slabs with profiled steel sheeting and steel I-beam [15]. The paper studied the mechanical behavior of shear connectors, which are used to advance the composite action between the steel beam and concrete. The study was conducted to look at the shear strength, stiffness, and ductility of demountable shear connectors in metallic decking composite slabs through push-off tests. The shear connectors are provided to interact between the steel beam-concrete slab composite structures that allow all parts to act as one-unit structures. The shear connectors' surfaces are embedded in the concrete slab, and the headed part of the connector is tied into the slab to resist the uplift forces. The collar edge of the shear connector is tied to the sheet and top flange steel beam with nut parts of the connector to transfer the load between the composite slab and steel beam within both reentrant and open trough profile steel sheeting. The shear connector used in the composite allows all components to have sufficient strength and stiffness, resist longitudinal shear, resist slip, resist uplift forces, as connection and load transmission. In general, the study of the composite slab with profiled steel sheeting and steel beam is rare when compared to a composite slab without profiled steel sheeting.

If the performance of the shear connectors between the concrete and steel part is not efficient in composite structures, problems like excessive slip formation, premature failures, the intractable problem, and induced fatigue problems have a high probability of occurrence. In addition, the construction of composite structures takes more time if the shear connection is not fabricated. The main objective of this paper was to investigate the performance of demountable shear connections in composite slab and steel I-section beams with reentrant and open trough profiled steel sheeting. An advanced nonlinear finite element modeling was accurately used in Abaqus 4.16 software package. In the investigation, the effects of adding profiled steel sheeting dimension and type in the composite structure made of composite slab and steel beam bonded by shear connector were considered to evaluate the strength and capacity of the demountable shear connectors. Shear connector diameter, geometries of reentrant and open trough profiled steel sheeting, dilation angle, and strength of concrete are the main parameters considered in the study. Further, the result obtained from finite element analysis is compared to the empirical formula provided by Eurocode for the prediction of shear capacity of studs in the composite structure; and sensitivity analysis was conducted to investigate the effect of input parameters on output parameter.

\section{Nonlinear FE Modelling}

2.1. General. A total of 24 specimens were modeled in FE simulation to cover the objective of the study. One additional control specimen was created and analyzed in Abaqus software as validation to determine the shear capacity and failure modes of the demountable shear connector in composite slab and steel I-section beam. The headed and embedment surface of the demountable stud connectors interacted with the slab against uplift forces, and the nodes of the collars were tied to profiled steel sheeting. The surface of the collar has interacted with a steel I-beam. At the top of the beam, a displacement was applied, which is restrained against all degrees of freedom, and also there were castrated or fixed at the bottom surface of the composite slab with restricted symmetry surface of the slab and beam web to resist the movement during displacement applied at top face of the beam. For the study, the nonlinear finite model in the Abaqus software package was considered [16], which has a wide capability of capturing material nonlinearity response. All components associated with the demountable shear connection were properly modeled to obtain accurate output from the finite element model. These parts include concrete slab, steel beam, profiled steel sheeting, reinforcement bars, and demountable shear connector. Both geometric and material nonlinearity was taken into consideration in the finite element model. An experimental test [15] was used to verify the simulation results obtained from FE analysis. Abaqus software is a general-purpose finite element software that is used to simulate the push-off test and has been widely used in previous research. The dynamic explicit analysis approach was applied in the study and only a quarter of the geometry of the push-off test was created due to the symmetrical conditions across the centerline of the web of the steel beam to save computational time. The main components of the FE model included the profiled steel decking, concrete slab, steel beam, reinforcement steel cage, and demountable shear connector. All parts were modeled separately and assembled to form one-quarter models of the push-off test specimen.

2.2. Parametric Study. To investigate the performance of the headed stud demountable shear connector, the diameter of studs, dilation angle, strength of concrete, 
dimension of the slab, and profiled steel sheeting were considered to be the primary parameters for this study. Figures 1(a) and 1(b) and Figures 2(a) and 2(b) illustrate the dimension of open through and reentrant profiled steel sheeting, respectively, which were taken as a parametric study in this paper. The thickness of the profiled steel sheeting was $1.0 \mathrm{~mm}$, which is constant for all specimens. However, the different height of sheet $\left(h_{p}\right)$ and width of rib $\left(b_{o}\right)$ of profiled steel sheeting, concrete strength, and diameter of shear connectors has been considered as parametric study according to Table 1 . The cross section of the steel I-section beam was taken to be $203 \times 203 \times 52$ $(\mathrm{mm} \times \mathrm{mm} \times \mathrm{mm})$ from a European universal beam and the dimension of the composite slab $(343.15 \mathrm{~mm} \times 150 \mathrm{~mm})$ was taken according to Eurocode 4 [17].

2.3. Parts (Geometry) Modeling. There are different parts created in the model. These parts include concrete slab, reinforcement bar, open through and reentrant profiled steel sheeting, demountable shear connector, and steel I-beams, as shown in Figure 3. Concrete slabs and steel-section beams are modeled on a 3D modeling space as deformable types with solid and extrusion base features. The shear connectors are modeled on a 3D modeling space as a deformable type with solid and revolution base features. In another case, reinforcement cage parts are modeled on a $2 \mathrm{D}$ modeling space as deformable type with wire and planar base feature, and both reentrant and open trough profile steel sheeting parts are modeled on a 3D modeling space as deformable type with shell and extrusion base feature.

2.4. Material Modelling. It is understandable that the failures may occur either in concrete, shear connector, or combination of the two parts. Therefore, a suitable material model is very important for the accuracy of the FE model. The finite element model can capture the behavior of concrete, steel, and shear connectors under arbitrary loading, including dynamic loading. Isotropic damaged elasticity in tension and compression was employed to present the inelastic behavior of concrete. Describing the stress softening function of the cracking concrete primarily based on the connection among the following failure strain and the cracking stress via the normative uniaxial constitutive relation presented in [18]. The concrete damage plasticity model can deal with two basic failure modes, compressive crushing and tensile cracking of concrete [19]. In this study, the concrete damage plasticity model was adopted and the maximum tensile strength of concrete was taken as $10 \%$ of its compressive strength.

In this paper, the Eurocode-2 [20] was used to compute the concrete elastic modulus $\left(\mathrm{E}_{\mathrm{cm}}\right)$. For concrete, a poison's ratio of 0.2 and a density of $2400 \mathrm{~kg} / \mathrm{m} 3$ were considered in the modeling. The Concrete Damaged Plasticity model which contains both compressive and tensile behavior equations for damage parameters to capture damage behavior and the modeling approaches are developed by checking the model sensitivity against mesh density, dilation angle, and fracture energy of concrete [21]. The stress-strain relationship of concrete for nonlinear analysis is taken from Eurocode 2 [20]. In this circumstance, the value of 0.0022 and 0.0035 was taken at peak and the nominal ultimate strain, respectively. Concrete compressive cylinder strength having a magnitude of 40,50 , and $60 \mathrm{MPa}$ has been used for the modeling. Furthermore, the material properties for steel I-beam, profiled steel sheeting, reinforcement bar, and shear connector have been proposed in the model based on Eurocode provision as illustrated in Table 2. The bilinear stress-strain model was used for both structural and reinforcement steel, as presented in [22].

2.5. Part Assembly in Model. After material properties, profiles and sections were created and assigned for the parts; instances were created for all components and assembled to their relative position. All elements of the dependent instance were employed in $F E$ simulation. Figures 4(a) and 4(b) show the assembled model based on the proposed steel profiled steel sheeting shape.

2.6. Boundary Conditions, Loading, Analysis Steps, and Interactions. The dynamic explicit analysis was used to analyze the Finite Element models. To save computational time, one-quarter of the push-out test specimen was built into the model. Once all the parts of the push-off test model are assembled, as shown in Figure 5, the appropriate contact interactions are defined between interacting surfaces of different components. The contact pair method is used to define the surface-to-surface contact between the concrete slab and the metal-profiled decking. The normal behavior is assumed to be hard because this type of normal behavior allows minimum penetration of the slave surface into the master surface. The penalty method is used to define the tangential friction with a coefficient of 0.4 and 0.5 , which can give more reliable results. The contacts between the steel beam, demountable shear connector, and nut were also defined using the contact pair method. The normal behavior is defined as hard contact and the tangential behavior is defined as penalty frictional with a coefficient of 0.50 and others that interact directly with shear connector were the same unless profiled steel sheeting to demountable shear connector interacted as tied through nodal. All nodes of the concrete slab at the base are fully fixed (castrated) along $Z$ directions, symmetry in $x$-direction surfaces of the models, and $y$-direction surfaces on the web of steel beam, as shown in Figure 5. The reinforcement steel cage truss elements are embedded inside the solid elements of concrete using embedded constraint as it is assumed that no slip or deboning occurred between the concrete and steel bars.

A displacement of $9.5 \mathrm{~mm}$ applied at the top of a steel beam with $0.2 \mathrm{sec}$ time interval incrementation, which is taken from the push-off test done by [15] considered as a control specimen using the displacement control method. The total force applied to the specimen was calculated by summing up the vertical reaction forces for the loading surface. 

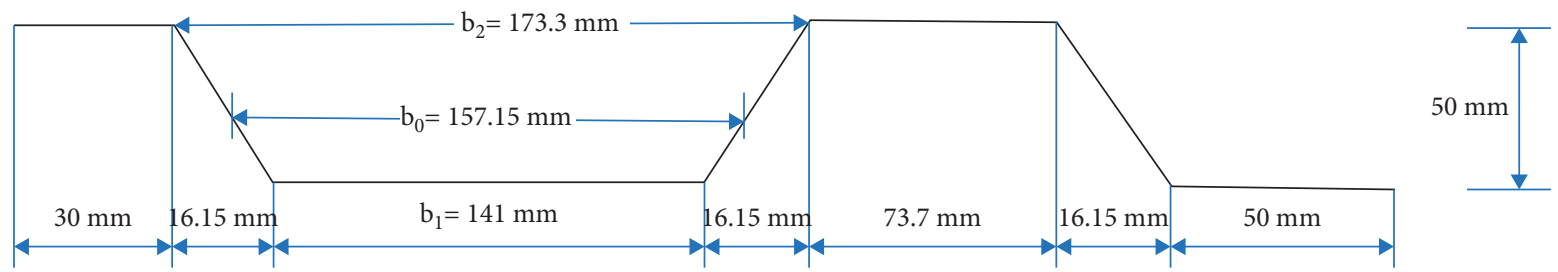

(a)
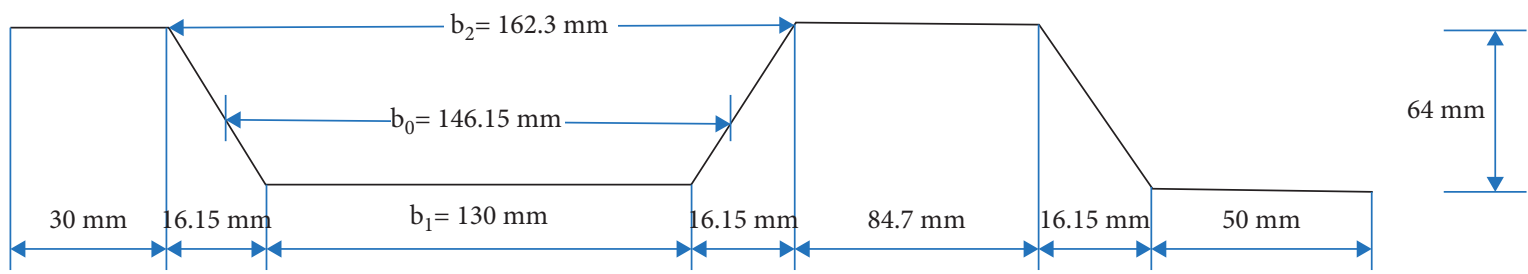

(b)

Figure 1: Definition of symbols for open through profiled steel sheeting including dimensions.
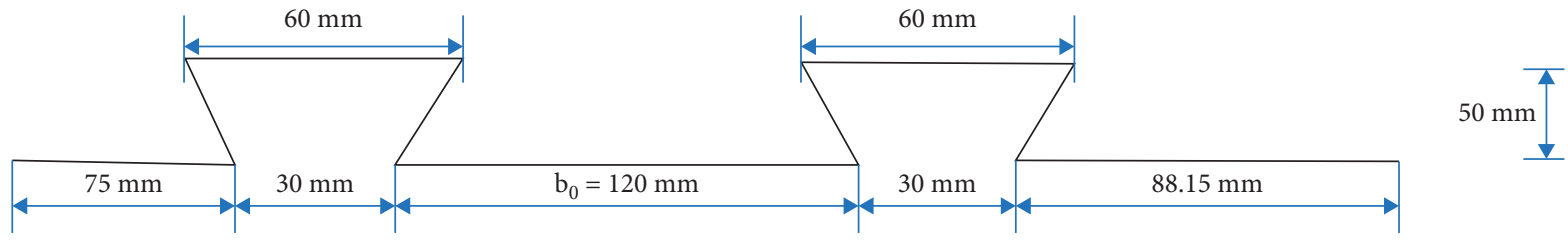

(a)
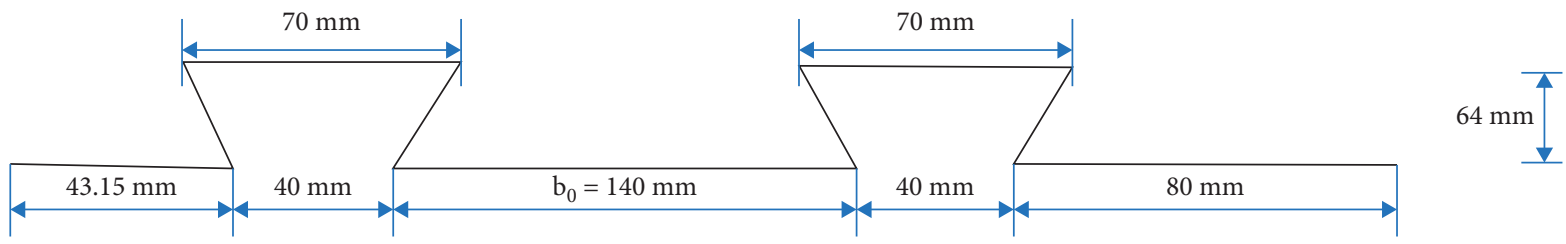

(b)

Figure 2: Definition of symbols for reentrant profiled steel sheeting including dimensions.

Table 1: Geometric dimensions and concrete strength as parametric study.

\begin{tabular}{|c|c|c|c|c|c|c|c|}
\hline \multicolumn{8}{|c|}{ Dimension } \\
\hline \multirow[t]{2}{*}{ Group } & \multirow[t]{2}{*}{ Specimen } & \multicolumn{3}{|c|}{ Profiled steel sheeting } & \multicolumn{2}{|c|}{ Stud } & \multirow[t]{2}{*}{ Concrete strength $(\mathrm{MPa})$} \\
\hline & & Figure & $b_{o}(\mathrm{~mm})$ & $h_{p}(\mathrm{~mm})$ & $d(\mathrm{~mm})$ & $h(\mathrm{~mm})$ & \\
\hline \multirow{3}{*}{ G1 } & SP-01 & $1(\mathrm{a})$ & 157.15 & 50 & 19 & 110 & 40 \\
\hline & SP-02 & $1(\mathrm{a})$ & 157.15 & 50 & 19 & 110 & 50 \\
\hline & SP-03 & 1(a) & 157.15 & 50 & 19 & 110 & 60 \\
\hline \multirow{3}{*}{ G2 } & SP-04 & $1(\mathrm{a})$ & 157.15 & 50 & 22 & 110 & 40 \\
\hline & SP-05 & $1(\mathrm{a})$ & 157.15 & 50 & 22 & 110 & 50 \\
\hline & SP-06 & $1(\mathrm{a})$ & 157.15 & 50 & 22 & 110 & 60 \\
\hline \multirow{3}{*}{ G3 } & SP-07 & $1(\mathrm{~b})$ & 146.15 & 64 & 19 & 110 & 40 \\
\hline & SP-08 & 1(b) & 146.15 & 64 & 19 & 110 & 50 \\
\hline & SP-09 & $1(\mathrm{~b})$ & 146.15 & 64 & 19 & 110 & 60 \\
\hline \multirow{3}{*}{ G4 } & SP-10 & 1(b) & 146.15 & 64 & 22 & 110 & 40 \\
\hline & SP-11 & (b) & 146.15 & 64 & 22 & 110 & 50 \\
\hline & SP-12 & 1(b) & 146.15 & 64 & 22 & 110 & 60 \\
\hline \multirow{3}{*}{ G5 } & SP-13 & 2(a) & 120 & 50 & 19 & 110 & 40 \\
\hline & SP-14 & 2(a) & 120 & 50 & 19 & 110 & 50 \\
\hline & SP-15 & 2(a) & 120 & 50 & 19 & 110 & 60 \\
\hline \multirow{3}{*}{ G6 } & SP-16 & 2(a) & 120 & 50 & 22 & 110 & 40 \\
\hline & SP-17 & 2(a) & 120 & 50 & 22 & 110 & 50 \\
\hline & SP-18 & 2(a) & 120 & 50 & 22 & 110 & 60 \\
\hline
\end{tabular}


TABle 1: Continued.

\begin{tabular}{|c|c|c|c|c|c|c|c|}
\hline \multicolumn{8}{|c|}{ Dimension } \\
\hline \multirow[t]{2}{*}{ Group } & \multirow[t]{2}{*}{ Specimen } & \multicolumn{3}{|c|}{ Profiled steel sheeting } & \multicolumn{2}{|c|}{ Stud } & \multirow[t]{2}{*}{ Concrete strength $(\mathrm{MPa})$} \\
\hline & & Figure & $b_{o}(\mathrm{~mm})$ & $h_{p}(\mathrm{~mm})$ & $d(\mathrm{~mm})$ & $h(\mathrm{~mm})$ & \\
\hline \multirow{3}{*}{ G7 } & SP-19 & $2(b)$ & 140 & 64 & 19 & 110 & 40 \\
\hline & SP-20 & 2(b) & 140 & 64 & 19 & 110 & 50 \\
\hline & SP-21 & $2(\mathrm{~b})$ & 140 & 64 & 19 & 110 & 60 \\
\hline \multirow{3}{*}{ G8 } & SP-22 & $2(b)$ & 140 & 64 & 22 & 110 & 40 \\
\hline & SP-23 & 2(b) & 140 & 64 & 22 & 110 & 50 \\
\hline & SP-24 & $2(b)$ & 140 & 64 & 22 & 110 & 60 \\
\hline
\end{tabular}

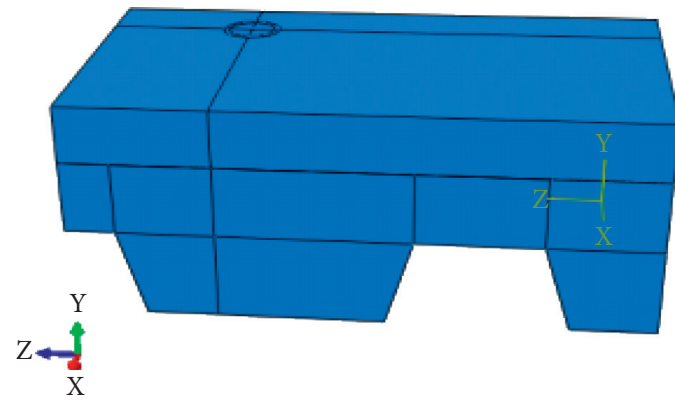

(a)

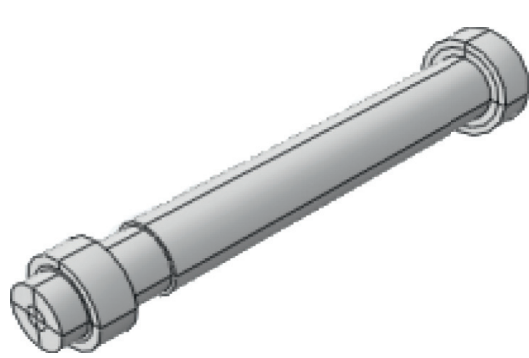

(c)

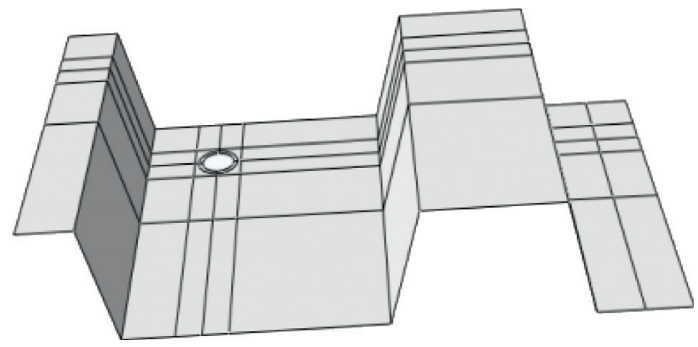

(e)

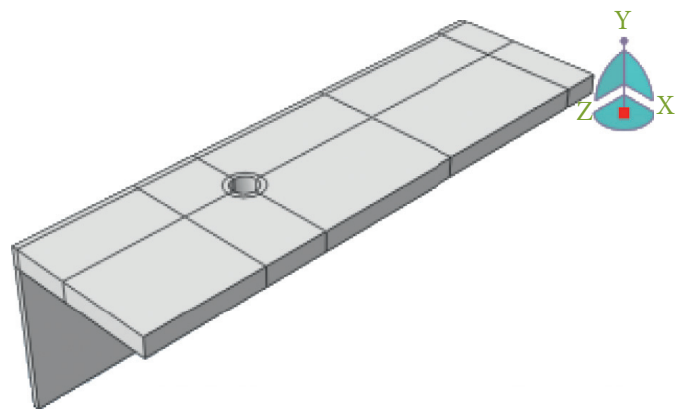

(b)
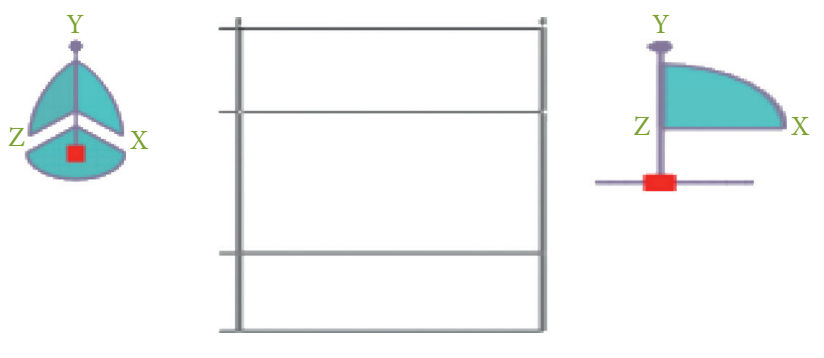

(d)

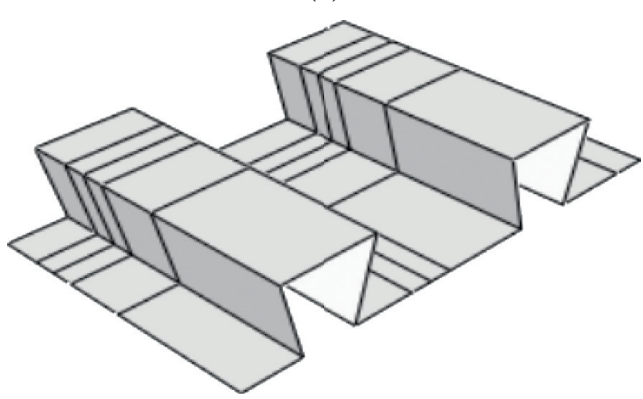

(f)

FIGURE 3: Parts modeled in FE software package.

TABLE 2: Material properties for steel I-beam, profiled steel sheeting, reinforcement bar, and shear connector.

\begin{tabular}{|c|c|c|c|c|c|}
\hline Part & Yield strength (GPa) & Poisons ratio & Ultimate strength (GPa) & Ultimate strain (\%) & Elastic modulus (GPa) \\
\hline Steel I-beam & 610 & 0.3 & 640.5 & 10 & 210 \\
\hline Profile sheet & 450 & 0.3 & 472.5 & 10 & 210 \\
\hline Reinforcent bar & 610 & 0.3 & 640.5 & 10 & 210 \\
\hline Shear connector & 610 & 0.3 & 640.5 & 10 & 210 \\
\hline
\end{tabular}




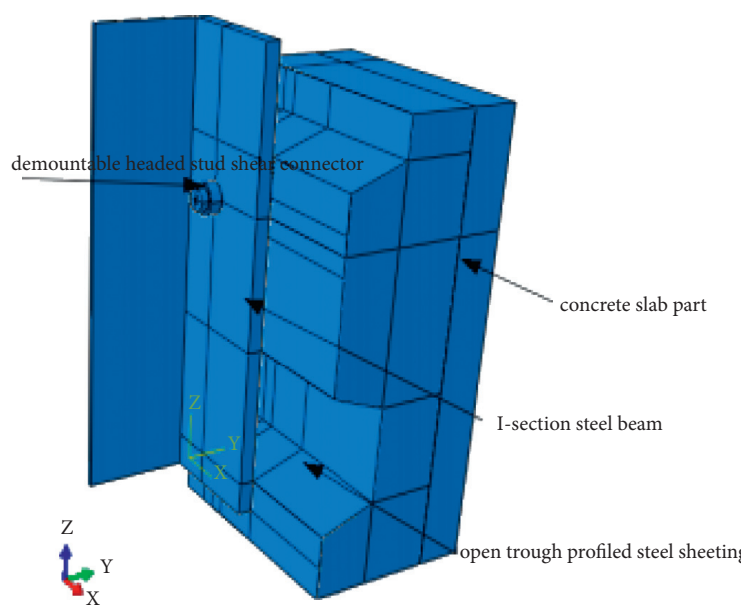

(a)

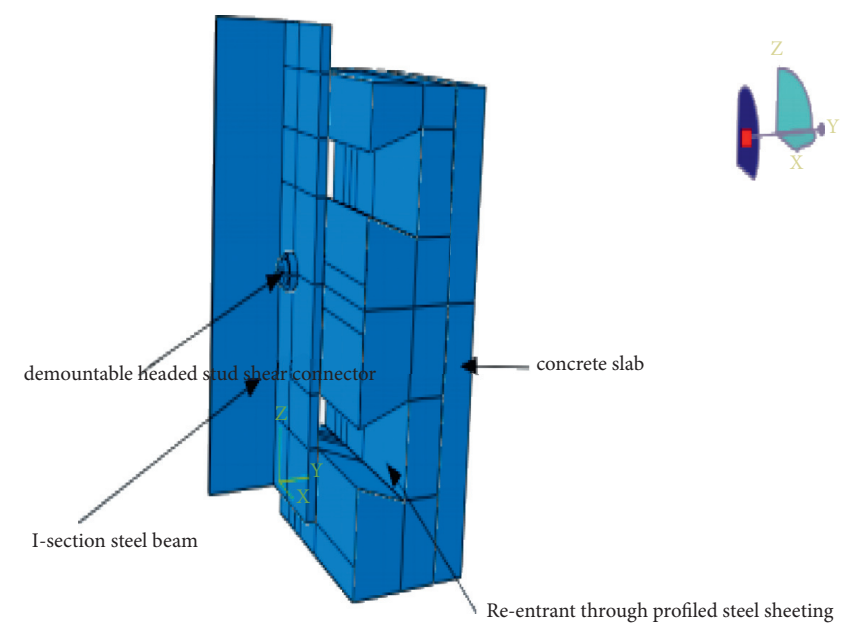

(b)

FIgURE 4: Assembled model with (a) open through and (b) reentrant profiled steel sheeting.

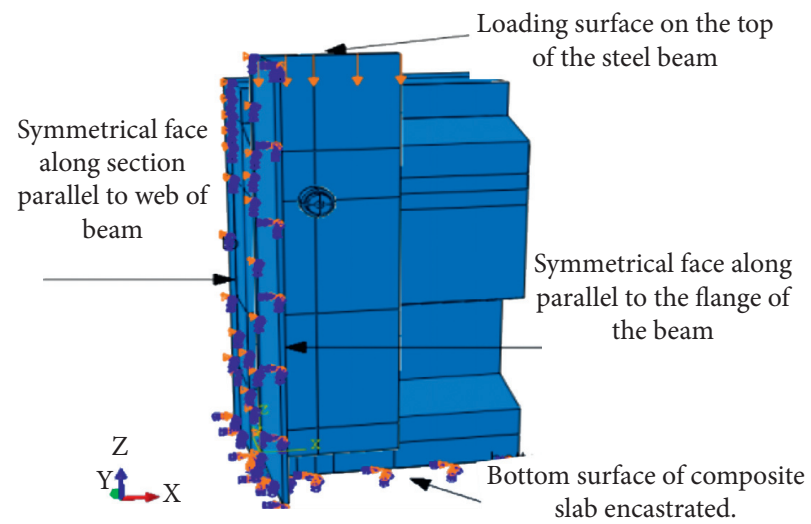

FIgURE 5: FE Model with boundary conditions, loading, and interactions.

2.7. Meshing and Element Types. Meshing size of all the parts in the models was summarized in Table 3. The size of the mesh was determined after a number of iterations until the FE simulation result became constant. Figure 6 shows the meshed component of the composite slab with a steel beam.

\section{Results and Discussion}

3.1. Validation of the FE Analysis Model. Before starting modeling for all specimens, the validation was conducted against previously undertaken experimental investigation [15]. This specimen was nominated with M6 in the paper. The shear connector capacity, load slip behavior, and failure mode obtained from the FE models are compared with experimental observations. The FE model result showed a good agreement when compared to the experimental results. According to the experimental result, two main failure modes were observed. The first mode of failure is concrete cone slab crushing and cracks, which happened without shear connector fracture. The concrete around the connector is failed in compression before the shear connector reached its ultimate capacity. The crushing of concrete started from the head of the shear connector through its depth in the concrete slab, forming a cone shape. The second mode of failure is shear connector fracture or yielding before concrete slab crushing. Figures 7(a) and 7(b) show the comparison of finite element analysis and experimental results regarding modes of failure of each component of the model.

Table 4 illustrates the shear connector ultimate shear capacity and slip of finite element and experimental model. As understood from Figure 7(b), the demounted shear connector was failed as fracture and deformed more at collar surfaces of stud and interacting face with concrete, respectively. Figure 8 indicates the shear capacity versus slip curve of the shear connector of both experimental and finite element models.

\subsection{Effects of Change in Rib Depth of Profiled Steel Sheeting on} the Performance of Shear Connection. Figures 9(a) and 9(b) show the load per stud versus slip curve extracted from finite element results for specimens (SP-04 \& SP-10) and (SP-15 \& $\mathrm{SP}-21)$, respectively. The specimens in each graph have the same concrete strength, profiled steel sheeting type, diameter shear stud, and concrete slab. However, a different 
TABLE 3: Meshing size and element types for all parts in the models.

\begin{tabular}{|c|c|c|}
\hline Parts & $\begin{array}{l}\text { Mesh size } \\
(\mathrm{mm})\end{array}$ & Element type \\
\hline Steel beam & 12.5 & C3D8R: An 8-node linear brick, hourglass control, reduced integration \\
\hline Concrete slab & 12 & C3D8R: An 8-node linear brick, hourglass control, reduced integration \\
\hline Profiled steel sheeting & 12 & $\begin{array}{l}\text { S4R: A 4-node doubly curved thin or thick shell, hourglass control, reduced integration, finite } \\
\text { membrane strains }\end{array}$ \\
\hline $\begin{array}{l}\text { Demountable shear } \\
\text { connector }\end{array}$ & 15 & C3D8R: An 8-node linear brick, hourglass control, reduced integration \\
\hline Reinforcement bar & 30 & T3D2: A 2-node linear 3-D truss \\
\hline
\end{tabular}

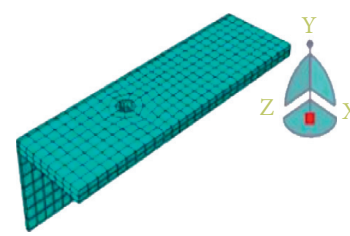

(a)

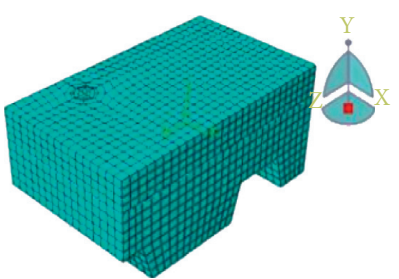

(b)

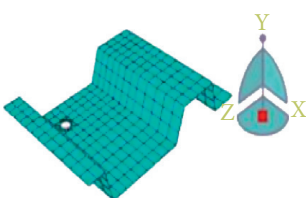

(c)

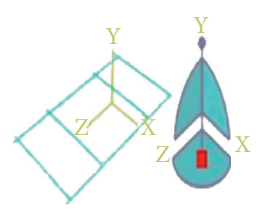

(d)

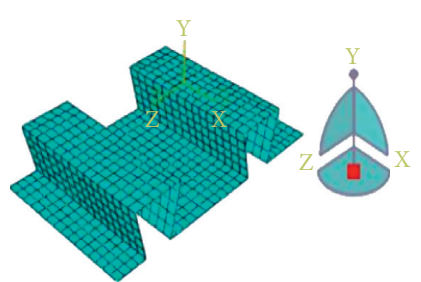

(e)

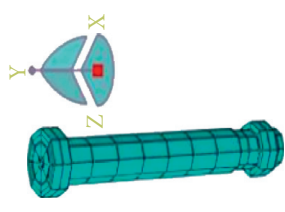

(f)

FIGURE 6: Meshing each part of the composite structure.
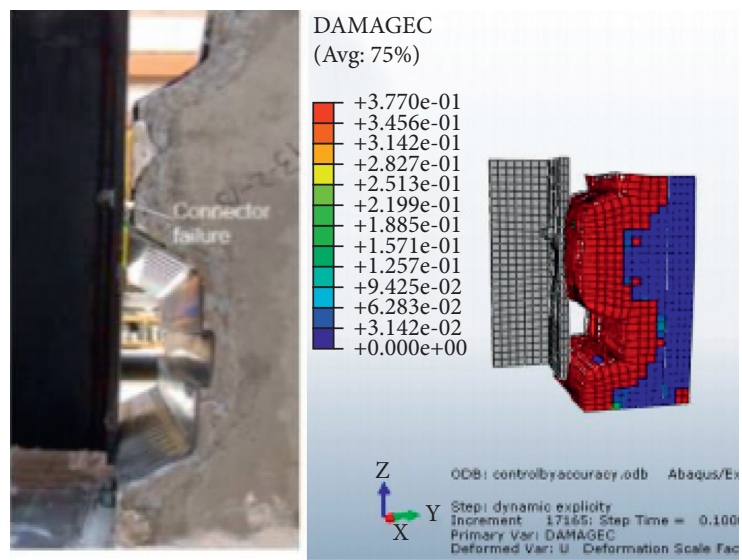

(a)
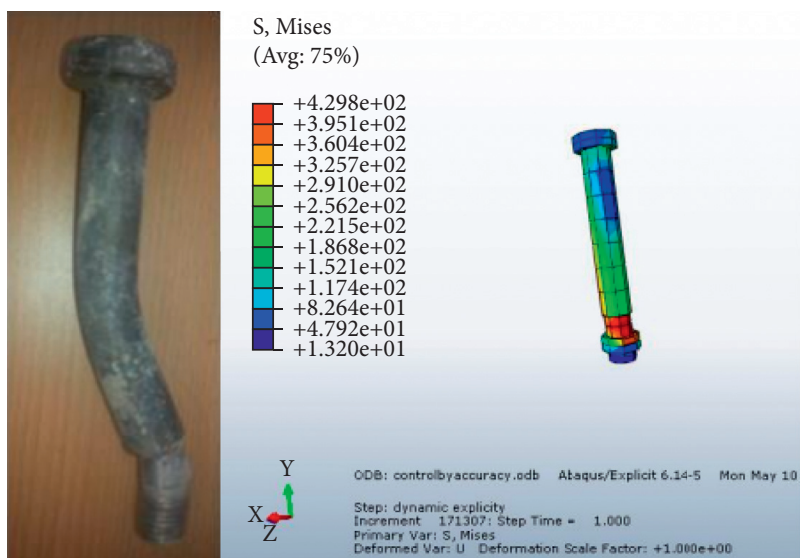

(b)

Figure 7: Comparison of FE model and experimental result: (a) Failure mode of concrete slab and (b) Deformed shape of the shear connector.

TABle 4: Comparison between FEA models and experimental results.

\begin{tabular}{lcccc}
\hline Test specimen & Parameters & FE model result & Experimental result & \% of difference \\
\hline Control & Ultimate load of connectors $(\mathrm{KN})$ & 79.879 & 82.6 & 3.29 \\
Model & Slip $(\mathrm{mm})$ & 6.013 & 7.0 & 12.85 \\
\hline
\end{tabular}

dimension of the profiled steel sheeting was considered. It can be understood that the capacity of shear connectors was significantly affected by the geometric dimension of profiled steel sheeting, keeping other parameters constant. Considering the same diameter of the shear connector, the ultimate shear capacity significantly increased as the height of the 


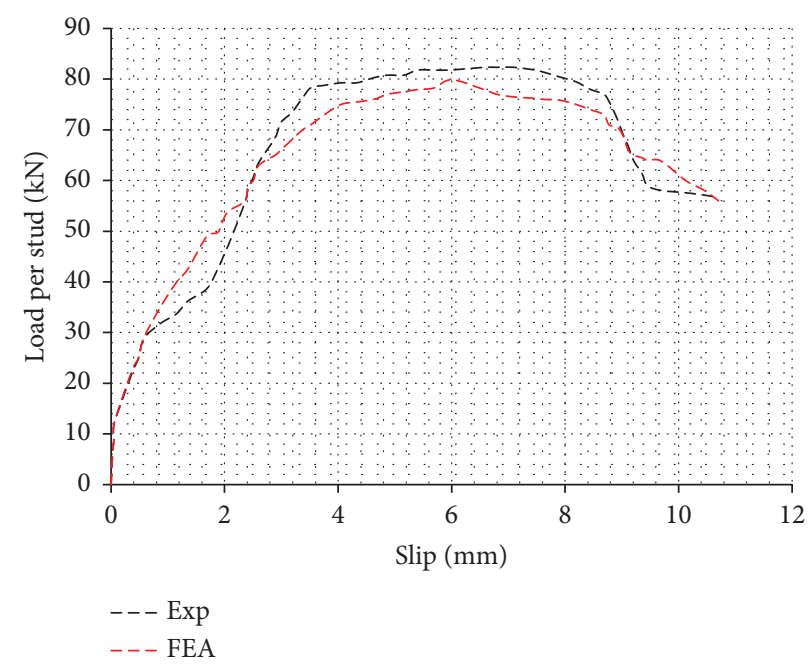

FIgURE 8: Comparison between FE model and experimental result.

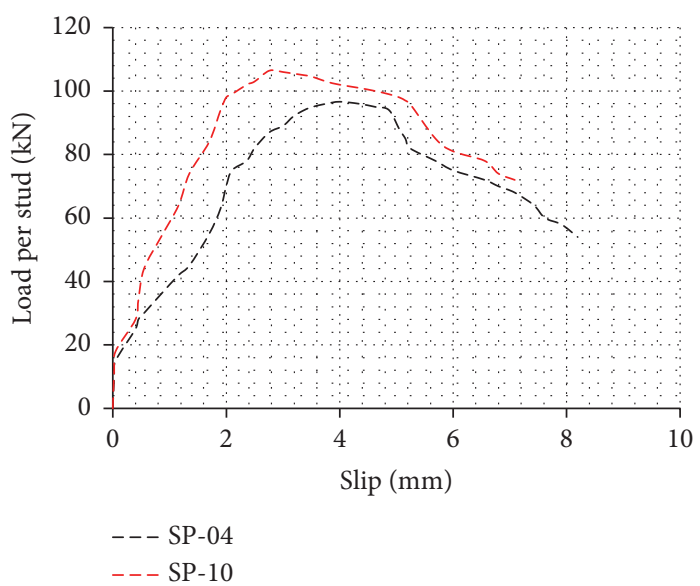

(a)

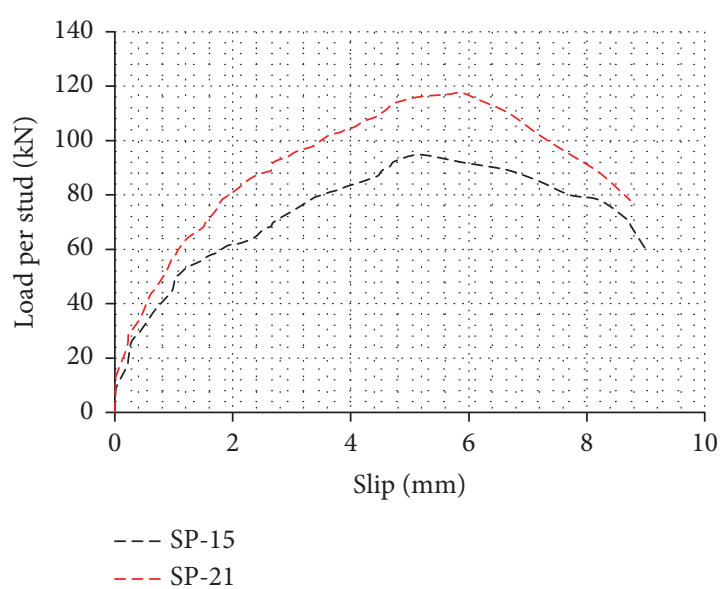

(b)

FIGURE 9: Effects of change in profiled steel sheeting rib depth on the capacity of the shear connector with (a) Open trough profiled steel sheeting and (b) Reentrant profiled steel sheeting.

profiled steel sheeting rib increased. The study verified that the capacity of the shear connector in the composite structures increased up to $11.601 \%$ and $32.564 \%$ when the open trough and reentrant profiled steel sheeting rib depth $\left(h_{\mathrm{p}}\right)$ increased from $50 \mathrm{~mm}$ to $64 \mathrm{~mm}$, respectively. Therefore, the profiled steel sheeting dimension is one of the determinant parameters that need to be considered to design a safe and economic composite structure.

\subsection{Effect of Change in Diameter of Shear Connector on Its} Shear Capacity. The study also investigated the effect of the diameter of the shear connector on its capacity for both open trough and reentrant profiled steel sheeting specimens using FE simulation. Figures $10(\mathrm{a})$ and 10 (b) present the load per connector versus slip curve of the specimens (SP-02 \& SP08) and (SP-05 \& SP-11) by considering the different diameters of the shear connector and the dimension of open through profiled steel sheeting, respectively. In another way,
Figures 11(a) and 11(b) present the load per connector versus slip curve of the specimens (SP-14 \& SP-20) and (SP$17 \&$ SP-23) by considering the different diameters of the shear connector and dimension of the reentrant profiled steel sheeting, respectively. The result showed the significant effect of the diameter of shear on its capacity in the composite structure. As the diameter of the shear connector increased from $19 \mathrm{~mm}$ to $22 \mathrm{~mm}$, the shear capacity is increased up to $54.313 \%$ and $28.903 \%$ for composite with open through and reentrant profiled steel sheeting, respectively.

3.4. Effects of Concrete Strength on the Capacity of Shear Connection. Figure 12 illustrates the effect of concrete compressive strength of composite structure with open through and reentrant profiled steel sheeting. As presented in Figures 12(a) and 12(b), the concrete strength has an enormous effect on the capacity of the shear connector when open through and reentrant profiled steel sheeting used, 


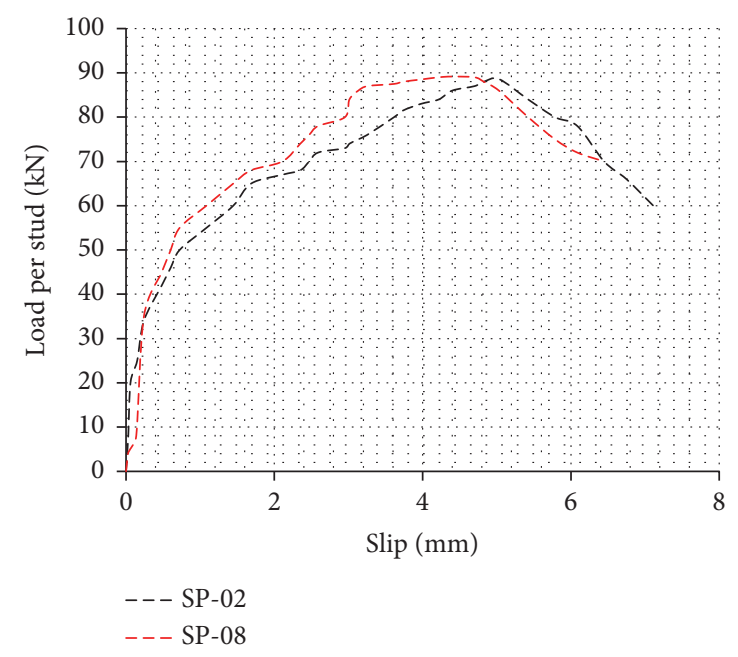

(a)

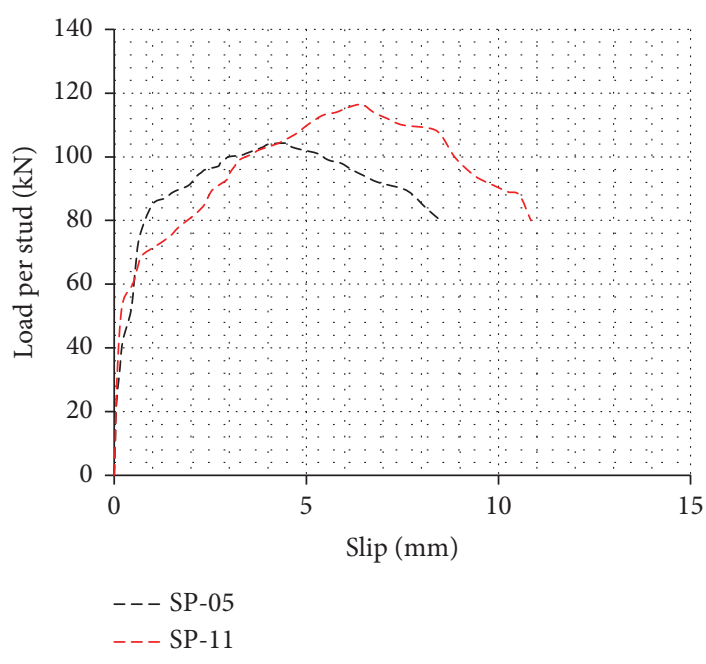

(b)

FIGURE 10: Effect of change in diameter of the connector on the capacity of shear connection with open through profiled steel sheeting [(a) $d=19 \mathrm{~mm}$ and (b) $d=22 \mathrm{~mm}]$.

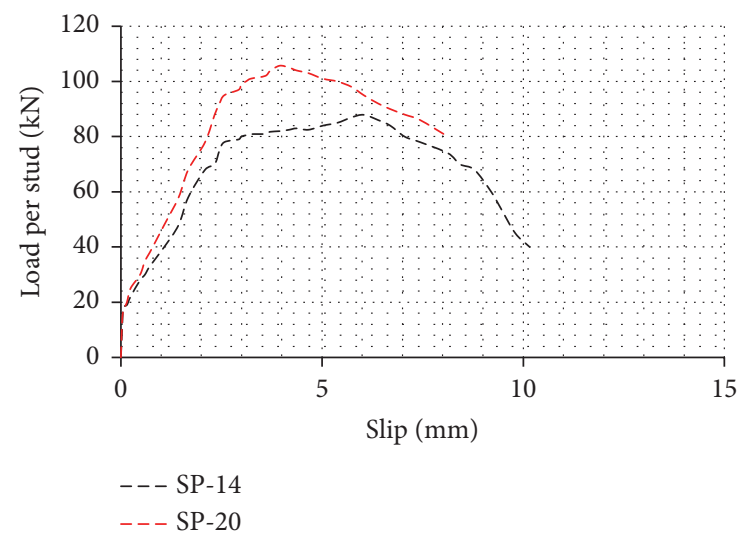

(a)

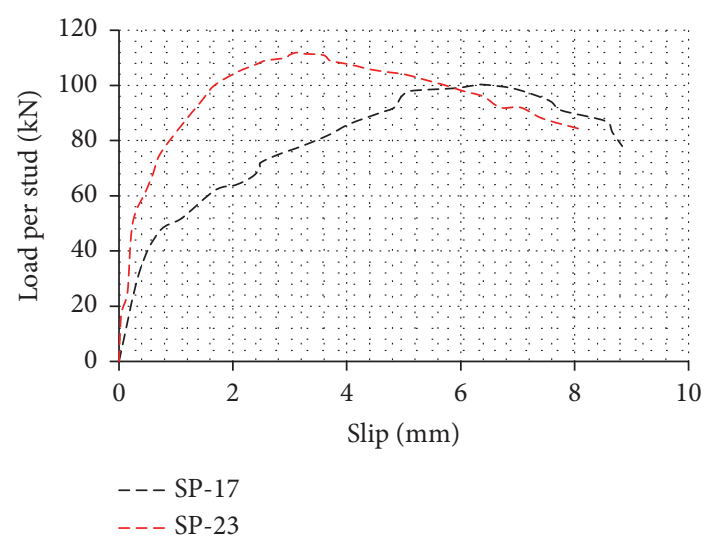

(b)

FIGURE 11: Effect of change in diameter of the connector on the capacity of shear connection with reentrant profiled steel sheeting [(a) $d=19 \mathrm{~mm}$ and $(\mathrm{b}) d=22 \mathrm{~mm}]$.

respectively. The presented shear connector capacity was analyzed in FE with a concrete grade of C-40, C-50, and C-60 by considering a different type of profiled steel sheeting as one parametric study. The capacity is significantly increased as the concrete grade increases. With the lower concrete grade, the concrete slab is crushed and cracked, but with a higher concrete grade, the shear connector is yielded. When concrete grade increases from C-40 to C-60, the capacity shear connector is increased up to $70.128 \%$ and $48.301 \%$ for open through and reentrant profiled steel sheeting.

\subsection{Damage and Failures of Composite Elements in the Models.} As observed from Figure 13, cracking and crushing occurred at the location around the shear connectors. Two types of failure happened based on the FE simulation result.
The concrete cone slab is crushed and cracked before shear connector yielding when low concrete compressive strength is employed in the Finite element simulation. In another way, the shear connector is yielded before concrete slab crushing when high concrete compressive strength is used. Therefore, concrete compressive strength has a role that determines the mode of failure in the composite structure.

Figure 14 presents the stress contour, which truly indicates the yielding and fracture of the demountable shear connector [Figures 14(a)-14(d)] and profiled steel sheeting [Figures $14(\mathrm{e})-14(\mathrm{~h})]$ with different study parameters. The failure modes of the shear connector and profiled steel sheeting were tremendously affected by concrete compressive strength. As high concrete compressive strength is employed, the shear connector is yielding and fractured 


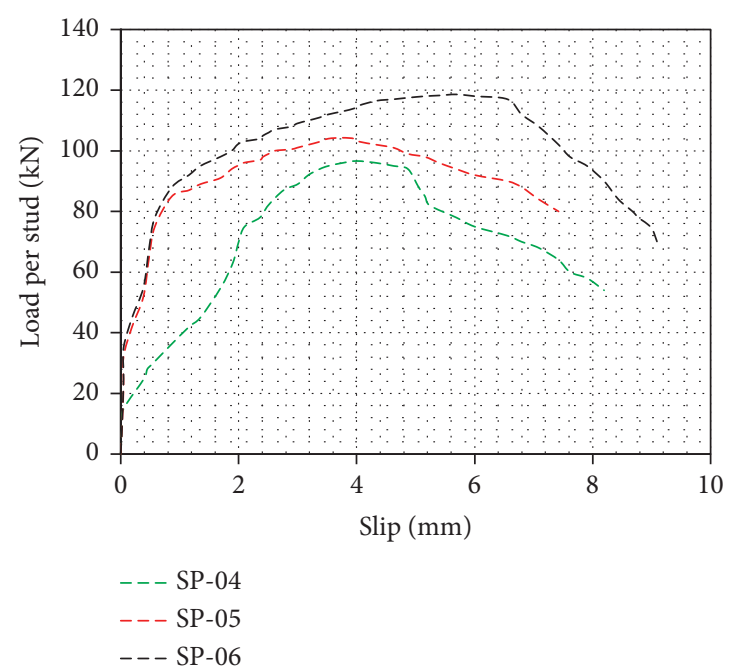

(a)

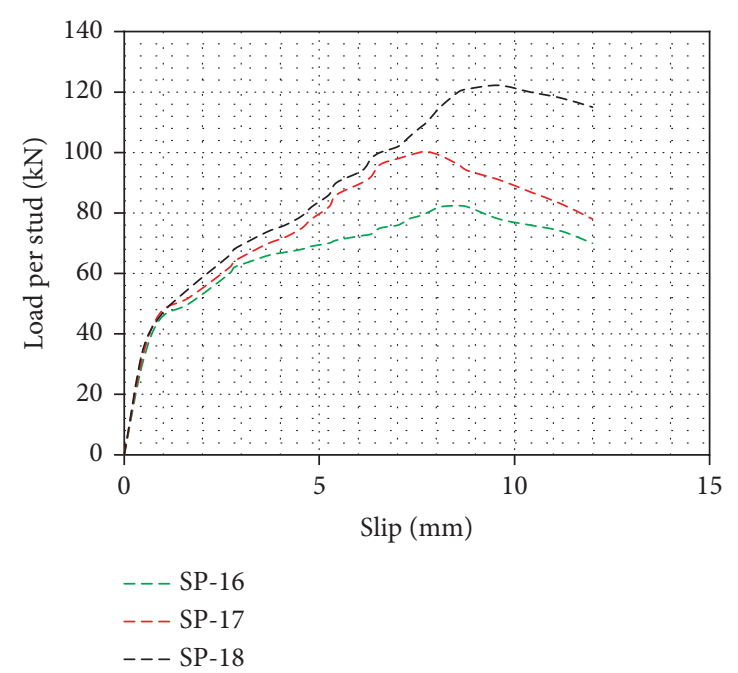

(b)

FIGURE 12: Effects of concrete strength on the capacity of shear connection with (a). Open through and (b). Reentrant profiled steel sheeting with C-40, C-50, and C-60 MPa.

before concrete cone slab crushing and cracking and vice versa as low concrete compressive strength is used.

\subsection{Comparison of Shear Connector Capacities Obtained from} Finite Element Analysis and Euro Code Specification. Table 5 shows the comparison of the shear connection capacities obtained from the finite element analysis and $\mathrm{Eu}-$ ropean Code 4 [17] empirical prediction provision. The Eurocode 4 predictions were generally conservative. However, in some cases, an overestimation of the shear capacity of the shear connector was obtained from $37.5 \%$ of the total specimens. Therefore, care to be needed during the design of such like composite structure to use the empirical formula provided by code. It can also be seen that the difference between the shear connection capacities obtained from the $\mathrm{FE}$ analysis and the design rules specified in the Eurocode is affected by study parameters. The mean values of $\mathrm{P}_{\mathrm{FE}} / P_{\mathrm{EC} 4}$ ratios are 1.057493 with the corresponding coefficients of variation $(\mathrm{COV})$ of 0.0439464 . The shear capacity of the connector is determined using equations (1)-(4), which is taken from Eurocode 4 provision.

$$
\begin{gathered}
P_{r}=K_{t} P_{r d}, \\
P_{r d}=\left.\min \right|_{\frac{0.29 \alpha d^{2} \sqrt{f_{c k} E_{c}}}{\gamma_{v}}} ^{\frac{0.8 f_{u} \pi d^{2},}{4 \gamma_{v}}} \\
\alpha=\left.\right|_{1, \quad} ^{0.2\left(\frac{h_{s c}}{d}+1\right) \quad \leq 1.0, \quad \text { for } 3 \leq \frac{h_{s c}}{d} \leq d,} \quad \text { for } \frac{h_{s c}}{d}>4,
\end{gathered}
$$

$$
K_{t}=\frac{0.7}{\sqrt{n_{r}}} \frac{b_{o}}{h_{p}}\left[\frac{h_{s c}}{h_{p}}-1\right] \leq 1.0
$$

where $d$ is the shear connector shank diameter in $\mathrm{mm}, h_{s c}$ is the shear connector height in $\mathrm{mm}, f_{u}$ is the shear connector ultimate tensile strength in $\mathrm{MPa}, f_{c k}$ is the characteristic cylinder compressive strength of concrete in $\mathrm{MPa}, E_{c}$ is the modulus of elasticity of concrete (MPa), $\gamma_{v}$ is the partial safety factor for shear resistance $\left(\gamma_{v}=1.25\right), b_{o}$ is the width of profiled steel sheeting in $\mathrm{mm}, h_{p}$ is the height of profiled steel sheeting in $\mathrm{mm}$.

3.7. Effect of Change Dilation Angle. Dilation angle plays a significant role in the performance of shear connection in composite slab and steel beam with profiled steel sheeting. The shear capacity of the stud was analyzed with FE simulation by taking different concrete compressive strengths for SP-10, SP-11, and SP-12 specimens. In this specimen, as the angle of dilation increases from 36 to 40 , the capacity of the shear connector increases up to $4.7 \%$, making other study parameters remains constant.

3.8. Sensitivity Analysis. Furthermore, multiple linear regression analysis was conducted with Statistical Package in Social Sciences (SPSS) Software package to investigate how much each dependent variable or parametric study affects the shear capacity of demountable stud connector in composite slab with profiled steel sheeting and steel I-beam. The finite element analysis result was used as the input parameter. Based on regression analysis, equation (5) was obtained, which is used to predict the shear capacity of the demountable connector in the composite structure. 


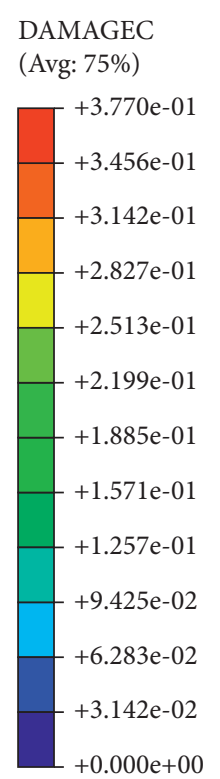

DAMAGEC (Avg: $75 \%$ )

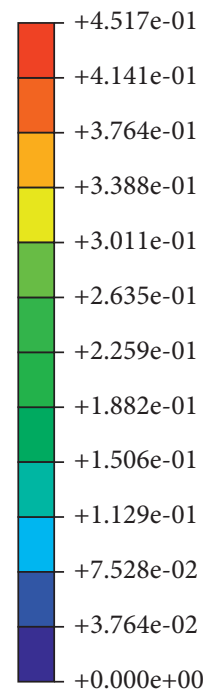

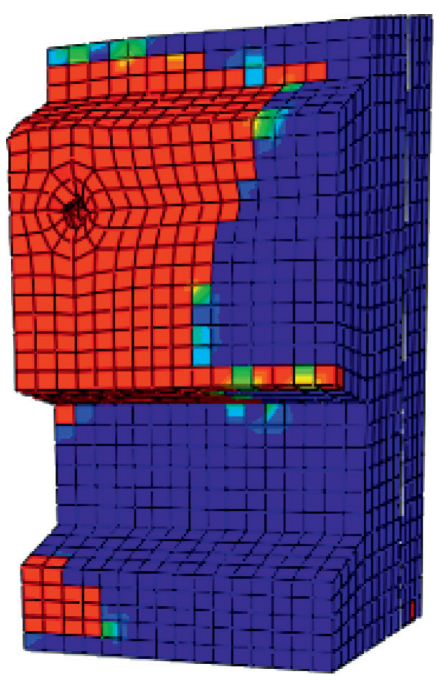

(a)

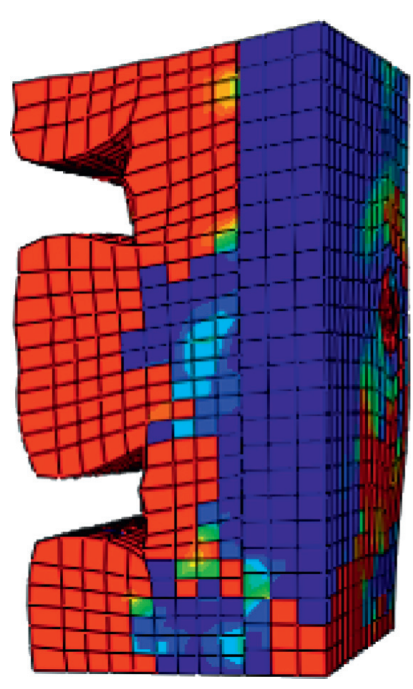

(c)
DAMAGEC

(Avg: $75 \%$ )
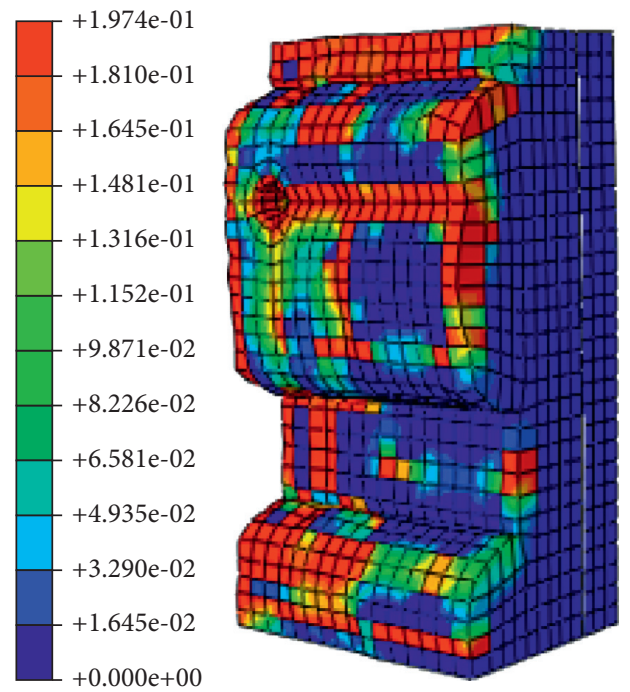

(b)

DAMAGEC (Avg: 75\%)

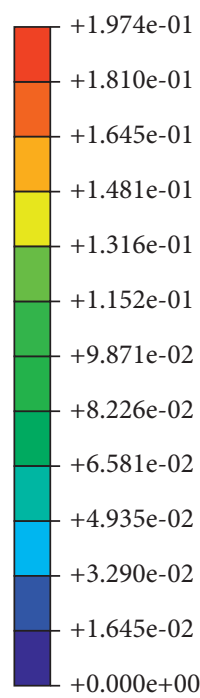

$+0.000 \mathrm{e}+00$

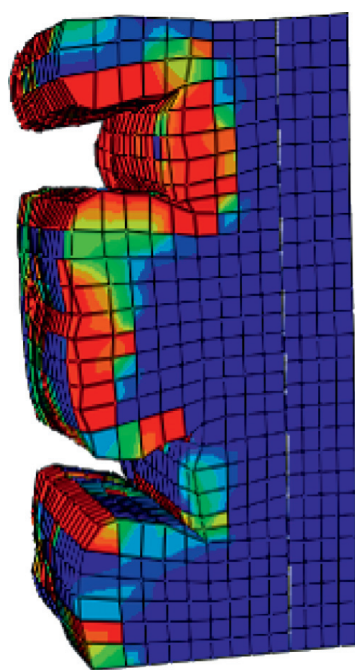

(d)

Figure 13: Damage mode of concrete cone slab within open trough $(a, b)$ and reentrant $(c, d)$ profiled steel sheeting shapes.

$$
\begin{aligned}
P_{r}= & 0.245413 b_{o}+0.344326 h_{p}+7.394444 d_{c}+1.24625 f_{c} \\
& -113.465
\end{aligned}
$$

where $P_{r}$ is the shear capacity shear connector $(\mathrm{kN}), b_{o}$ is the rib width of profiled steel sheeting $(\mathrm{mm}), h_{p}$ is the rib height of profiled steel sheeting $(\mathrm{mm}), d_{c}$ is the diameter of shear connector $(\mathrm{mm}), f_{c}$ is the concrete compressive strength $(\mathrm{MPa})$.
As it can be understood from equation (5), the diameter of the shear connector has a tremendous effect on its shear capacity concerning other parameters. The concrete compressive strength is the second parameter that has significance on the shear capacity of the connectors. In another case, rib height and width of profiled steel sheeting affect the shear capacity of shear connectors slightly when compared to the diameter of the shear connector and concrete compressive strength. 


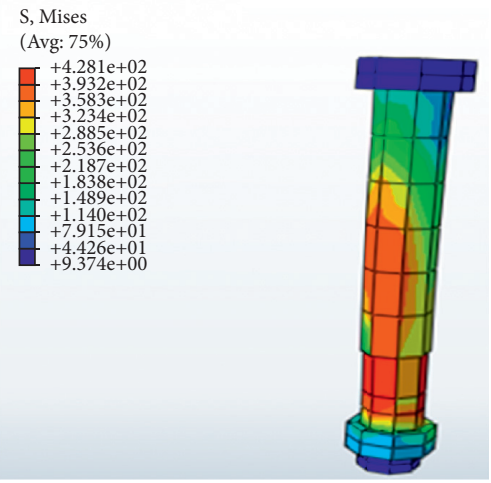

(a)

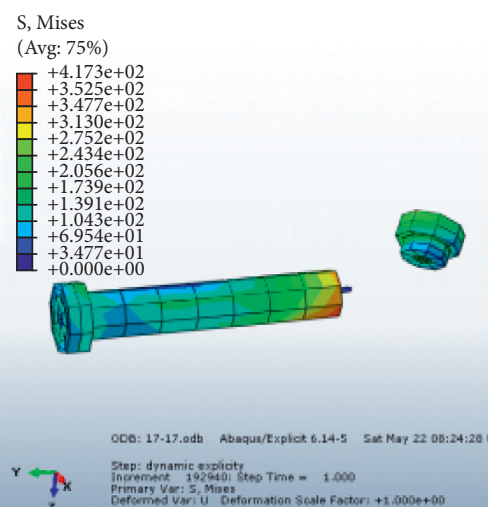

(c)
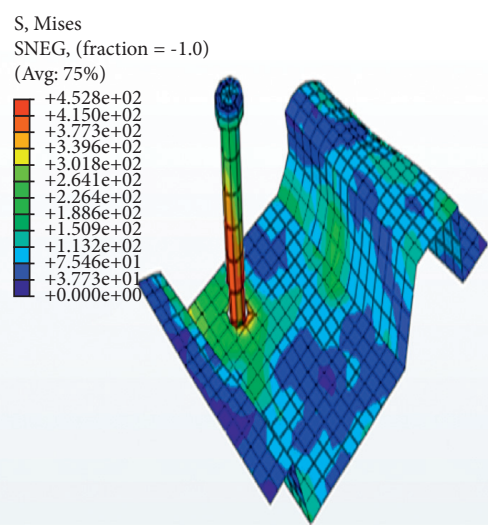

(e)

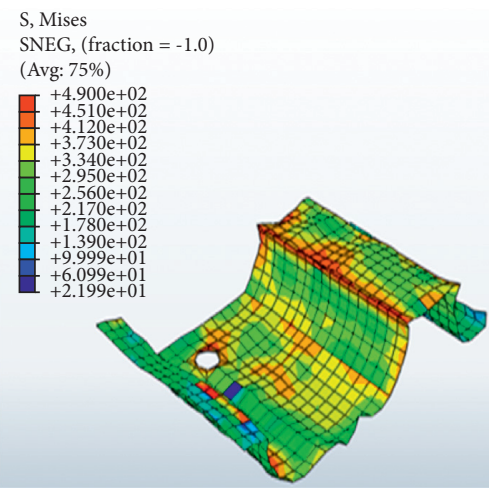

(g)

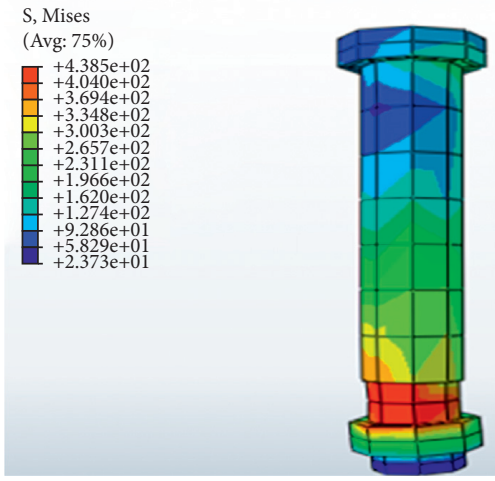

(b)

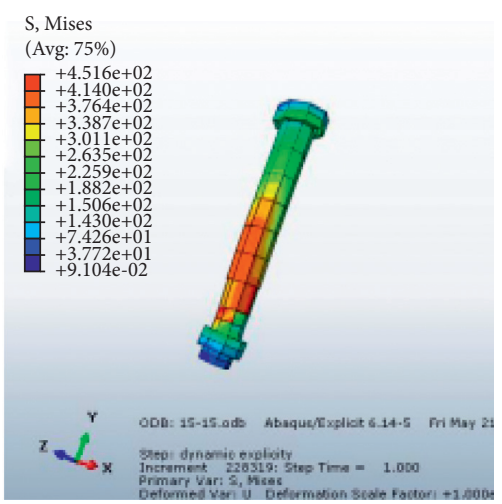

(d)

S, Mises

SNEG, $($ fraction $=-1.0)$

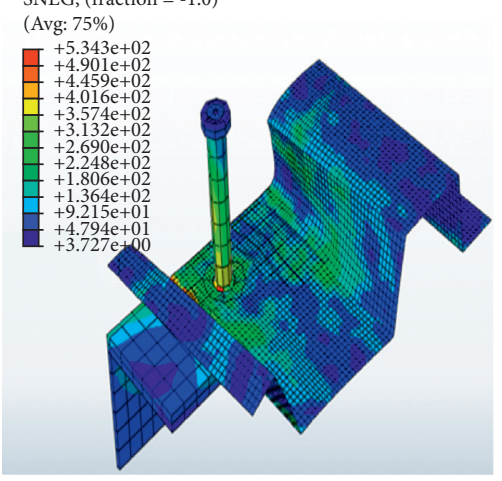

(f)

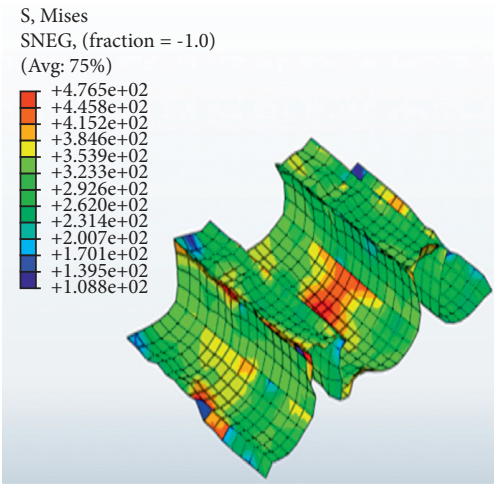

(h)

Figure 14: Failure modes of shear connector (a-d) and profiled steel sheeting (e-h) in the models. 
TABLE 5: Summaries of finite element analysis and Eurocode prediction of shear connector capacity for all model specimens.

\begin{tabular}{|c|c|c|c|c|}
\hline Group & Specimens & $P_{\mathrm{FE}}(\mathrm{KN})$ & $P_{\mathrm{EC} 4}(\mathrm{KN})$ & $P_{\mathrm{FE}} / P_{\mathrm{EC} 4}$ \\
\hline \multirow{3}{*}{ G1 } & SP-01 & 62.6 & 81.6 & 0.767157 \\
\hline & SP-02 & 88.6 & 81.6 & 1.085784 \\
\hline & SP-03 & 106.5 & 81.6 & 1.305147 \\
\hline \multirow{3}{*}{ G2 } & SP-04 & 96.6 & 109.5 & 0.882192 \\
\hline & SP-05 & 104.3 & 109.5 & 0.952511 \\
\hline & SP-06 & 118.6 & 109.5 & 1.083105 \\
\hline \multirow{3}{*}{ G3 } & SP-07 & 64.74 & 81.6 & 0.793382 \\
\hline & SP-08 & 89.17 & 81.6 & 1.09277 \\
\hline & SP-09 & 109.84 & 81.6 & 1.346078 \\
\hline \multirow{3}{*}{ G4 } & SP-10 & 106.4 & 109.5 & 0.971689 \\
\hline & SP-11 & 116.4 & 109.5 & 1.063014 \\
\hline & SP-12 & 132.3 & 109.5 & 1.208219 \\
\hline \multirow{3}{*}{ G5 } & SP-13 & 78 & 81.6 & 0.955882 \\
\hline & SP-14 & 87.91 & 81.6 & 1.077328 \\
\hline & SP-15 & 94.8 & 81.6 & 1.161765 \\
\hline \multirow{3}{*}{ G6 } & SP-16 & 82.4 & 109.5 & 0.752511 \\
\hline & SP-17 & 110.3 & 109.5 & 1.007306 \\
\hline & SP-18 & 122.2 & 109.5 & 1.115982 \\
\hline \multirow{3}{*}{ G7 } & SP-19 & 103.4 & 81.6 & 1.267157 \\
\hline & SP-20 & 105.7 & 81.6 & 1.295343 \\
\hline & SP-21 & 117.6 & 81.6 & 1.441176 \\
\hline \multirow{3}{*}{ G8 } & SP-22 & 89.1 & 109.5 & 0.813699 \\
\hline & SP-23 & 102.5 & 109.5 & 0.936073 \\
\hline & SP-24 & 110 & 109.5 & 1.004566 \\
\hline Mean & & & & \\
\hline $\mathrm{COV}$ & & & & \\
\hline
\end{tabular}

\section{Conclusion}

An advanced nonlinear FE simulation has been developed to access the shear capacity of stud in composite slabs with profiled steel sheeting and steel beam. In the study, the dimension and type of profiled steel sheeting, the diameter of the shear connector, concrete compressive strength, and dilation angle have been considered as study parameters. The models considered the nonlinear material properties of the concrete, steel beam, profiled steel sheeting, reinforcement bars, and headed stud shear connectors. The capacity of the shear connector, load-slip curve of stud, and failure modes were predicted from the finite element analysis. Based on the FE simulation and parametric study, the following conclusion was drawn:

(i) The concrete compressive strength significantly affects the capacity of a demountable shear connector. The capacity of the shear connector increased up to $70.128 \%$ and $48.301 \%$ with open trough and reentrant profiled steel sheeting, respectively, as concrete compressive strength increased from C-40 to C-60.

(ii) In addition, the geometry of profiled steel sheeting slightly affects the performance of the shear connector in composite structures in resisting the shear forces. It is affirmed that the ultimate shear resistance increased with the increase of the depth of the sheets. In this case, the capacity of the stud increased up to $11.601 \%$ and $32.564 \%$ as the open trough and reentrant profiled steel sheeting depth (hp) increased from $50 \mathrm{~mm}$ to $64 \mathrm{~mm}$, respectively.

(iii) Furthermore, the diameter of the shear connector tremendously affects the shear capacity of the stud when compared to other parametric studies. The sheer capacity of the connector increased up to $54.313 \%$ and $28.903 \%$ as the diameter of the stud increased from $19 \mathrm{~mm}$ to $22 \mathrm{~mm}$ with open trough and reentrant profiled steel sheeting, respectively.

(iv) Two types of failure have been identified based on finite element simulation. The first was concrete cone slab crushing and cracking before shear connector fracture, which happened in specimens with low concrete compressive strength. The second failure was stud fracture before crushing and cracking of concrete cone slab, which happened in specimens with high concrete compressive strength.

\section{Data Availability}

All the data are included in the paper.

\section{Conflicts of Interest}

The authors declare that they have no conflicts of interest. 


\section{Acknowledgments}

The authors would like to thank all who shared their time and resources for the paper.

\section{References}

[1] H. Du, X. Hu, Y. Meng, G. Han, and K. Guo, "Study on composite beams with prefabricated steel bar truss concrete slabs and demountable shear connectors," Engineering Structures, vol. 210, no. January, Article ID 110419, 2020.

[2] P. Arıkoğlu, E. Baran, and C. Topkaya, "Behavior of channel connectors in steel-concrete composite beams with precast slabs," Journal of Constructional Steel Research, vol. 172, Article ID 106167, 2020.

[3] A. Ataei and M. Zeynalian, "A study on structural performance of deconstructable bolted shear connectors in composite beams," Structures, vol. 29, no. December, pp. 519-533, 2021.

[4] M. Hosseinpour, M. Zeynalian, A. Ataei, and M. Daei, "Pushout tests on bolted shear connectors in composite coldformed steel beams," Thin-Walled Structures, vol. 164, no. September, p. 107831, 2021.

[5] D. Lam, "Capacities of headed stud shear connectors in composite steel beams with precast hollowcore slabs," Journal of Constructional Steel Research, vol. 63, no. 9, pp. 1160-1174, 2007.

[6] A. R. Alves, B. V. Isabel, B. V. Washintgon, and S. V. Gustavo, "Prospective study on the behaviour of composite beams with an indented shear connector," Journal of Constructional Steel Research, vol. 148, pp. 508-524, 2018.

[7] L. Tong, L. Chen, M. Wen, and C. Xu, "Static behavior of stud shear connectors in high-strength-steel-UHPC composite beams," Engineering Structures, vol. 218, no. March, Article ID 110827, 2020.

[8] A. Ataei, M. Zeynalian, and Y. Yazdi, "Cyclic behaviour of bolted shear connectors in steel-concrete composite beams," Engineering Structures, vol. 198, no. November, Article ID 109455, 2019.

[9] P. Arezoomand Langarudi and M. Ebrahimnejad, "Numerical study of the behavior of bolted shear connectors in composite slabs with steel deck," Structures, vol. 26, no. April, pp. 501-515, 2020.

[10] L. Bai, Y. Li, C. Hou, T. Zhou, and M. Cao, "Longitudinal shear behaviour of composite slabs with profiled steel sheeting and ECC," Engineering Structures, vol. 205, no. June, Article ID 110085, 2020.

[11] J. V. F. Dias, H. Carvalho, F. C. Rodrigues, K. A. F. P. Maia, and R. B. Caldas, "Experimental and numerical study on CFS composite beams with riveted shear connectors," Structures, vol. 33, no. July, pp. 737-747, 2021.

[12] P. Lacki, A. Derlatka, P. Kasza, and S. Gao, "Numerical study of steel-concrete composite beam with composite dowels connectors," Computers \& Structures, vol. 255, Article ID 106618, 2021.

[13] M. N. A. Salih, M. Md Tahir, S. Mohammad et al., "Bending experiment on a novel configuration of composite system using rebar as shear connectors with partially encased coldformed steel built-up beams," Materials Today Proceedings, vol. 39, no. xxxx, pp. 999-1005, 2021.

[14] J. Huo, H. Wang, L. Li, and Y. Liu, "Experimental study on impact behaviour of stud shear connectors in composite beams with profiled steel sheeting," Journal of Constructional Steel Research, vol. 161, no. xxxx, pp. 436-449, 2019.
[15] N. Rehman, D. Lam, X. Dai, and A. F. Ashour, "Experimental study on demountable shear connectors in composite slabs with profiled decking," Journal of Constructional Steel Research, vol. 122, pp. 178-189, 2016.

[16] A. Inc, "ABAQUS version 6.10-1 analysis user's manual," Dassault Systèmes Simulia Corp, vol. III, pp. 1-10, 2017, http:// 130.149.89.49:2080/v6.10/pdf_books/ANALYSIS_3.pdf.

[17] European Committee for Standardization, Eurocode 4: Design of Composite Steel and concrete Structures Part 1-1: General Rules and Rules for Buildings, European Committee for Standardization, Brussels, Belgium, 2004.

[18] W. Demin and H. Fukang, "Investigation for plastic damage constitutive models of the concrete material," Procedia Engineering, vol. 210, pp. 71-78, 2017.

[19] B. Alfarah, F. López-Almansa, and S. Oller, "New methodology for calculating damage variables evolution in Plastic Damage Model for RC structures," Engineering Structures, vol. 132, pp. 70-86, 2017.

[20] European Committee for Standardization, Eurocode 2: Design of concrete Structures - Part 1: General Rules and Rules for Buildings, Vol. 1, No. November, European Committee for Standardization, Brussels, Belgium, 2002.

[21] Y. Sümer and M. Aktaş, "Defining parameters for concrete damage plasticity model," Challenge Journal of Structural Mechanics, vol. 1, no. 3, pp. 149-155, 2015.

[22] S. Maleki and S. Bagheri, "Behavior of channel shear connectors, Part II: analytical study," Journal of Constructional Steel Research, vol. 64, no. 12, pp. 1341-1348, 2008. 